Res Pública Revista de Historia de las Ideas Políticas

ISSN: $1131-558 \mathrm{X}$

\title{
Noema, institución y universidad en el giro de la principialidad a la axiomática. Jacques Lezra, necrofilología y deconstrucción afirmativa
}

\author{
Gonzalo Díaz-Letelier ${ }^{1}$
}

Recibido: 29-04-2021 / Aceptado: 21-09-2021

\begin{abstract}
Resumen. En el siguiente ensayo intento una consideración amplia del problema de la institución fuerte a partir de la cuestión del doblez metafórico del lenguaje y su articulación metafísico-principial. Se trata de una cuestión problemática que cabría situar como un prolegómeno posible de acceso al pensamiento Jacques Lezra en torno a una cosmología heteróclita y una república material o salvaje -pensamiento según el cual el "republicanismo salvaje" dependería de producir e instituir conceptos defectivos de asociación política que den lugar a "instituciones defectivas". Para ello apunto al trabajo de Lezra sobre la trama de relaciones entre lenguaje, institución y deconstrucción en Paul de Man; a la paradigmática reductio ad unum en la institución del lenguaje y su maximización como unidad ideal del sentido y estructura lógica del mundo en la fenomenología de Edmund Husserl; a la necrofilología de Lezra como teoría materialista de los conceptos y de la inestabilidad ontológica del mundo; y, por último, a la cuestión del principio de equivalencia y traductibilidad general en la época del capitalismo global.
\end{abstract}

Palabras clave: institución; lenguaje; principialidad; lógica; anarquía del noema; materialismo; república.

\section{[en] Noema, Institution and University in the Turn from Principiality to Axiomatics. Jacques Lezra, Necrophilology and Affirmative Deconstruction}

\begin{abstract}
In the following essay I attempt a broad consideration of the problem of the strong institution starting from the question of the metaphorical double of language and its metaphysical-principial articulation. This is a problematic question that could be placed as a possible prolegomenon to Jacques Lezra's thought on a heteroclit cosmology and a material or savage republic -a thought according to which "savage republicanism" would depend on producing and instituting defective concepts of political association that give rise to "defective institutions". For this I point to Lezra's work on the web of relations between language, institution and deconstruction in Paul de Man; to the paradigmatic reductio ad unum in the institution of language and its maximization as an ideal unit of meaning and logical structure of the world in Edmund Husserl's phenomenology; to Lezra's necrophilology as a materialist theory of concepts and ontological instability; and finally to the question of the principle of general equivalence and translatability in the age of global capitalism.

Keywords: Institution; Language; Principiality; Logics; noema Anarchy; Materialism; Republic.
\end{abstract}

Sumario. 1. Lenguaje, institución y deconstrucción. 2. La institución del noema. 3. Necrofilología. 4. De la soberanía a la interfaz ampliada del capitalismo. Bibliografía

Cómo citar: Díaz-Letelier, G. (2022). Noema, institución y universidad en el giro de la principialidad a la axiomática. Jacques Lezra, necrofilología y deconstrucción afirmativa. Res Pública. Revista de Historia de las Ideas Politicas, 25(2), 23-30.

Por eso afirma con razón Lucrecio que la desviación quiebra las fati foedera (los pactos del destino), y como él aplica en seguida esto a la conciencia, se puede decir del átomo que la desviación es ese algo en su interior que puede luchar y resistir.

Karl $\operatorname{Marx}^{2}$
Esta analogía es el sitio mismo de lo teológico-político, el trazo de unión o traducción entre lo teológico y lo político; es también lo que articula la soberanía política, la encarnación cristiana del cuerpo de Dios (o Cristo) en el cuerpo del rey, los dos cuerpos del rey.

Jacques Derrida ${ }^{3}$

University of California Riverside

gdiaz049@ucr.edu

K. Marx, Diferencia de la filosofia de la naturaleza en Demócrito y en Epicuro, Madrid, Editorial Ayuso, 1971, p. 38

J. Derrida, "What is a «Relevant» Translation?", trad. L. Venuti, Critical Inquiry, X, 27, 2001, p. 197. 


\section{Lenguaje, institución y deconstrucción}

En junio de 2017, en la Facultad de Artes de la Universidad de Chile, Jacques Lezra ofreció una conferencia que versaba sobre alegoría e institución en Paul de $\mathrm{Man}^{4}$. En esa ocasión apuntó al trabajo que se ha estado haciendo sobre la base de algunos textos de Paul de Man que se encuentran en el archivo de su obra en la Universidad de California Irvine. Es entre esos materiales y el trabajo tardío de Paul de Man sobre la alegoría donde Lezra encuentra elementos para pensar, desde la deconstrucción, la cuestión de la institución. Institución y lenguaje: hablamos de las instituciones y el lenguaje es una institución. Y dentro de las instituciones del lenguaje, la figura retórica de la alegoría ha funcionado ella misma como alegorema de la idea de institución. ¿En qué consiste una "alegoría"? En griego

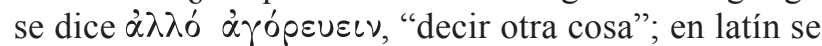
dice aliquid stat pro aliquo, "una cosa en lugar de otra cosa". Una mujer ciega con una balanza, alegoría de la justicia; un esqueleto que porta una guadaña, alegoría de la muerte; la salida de una tenebrosa caverna a la luz del sol, alegoría de la educación filosóficamente concebida según Platón. La alegoría pone a lo singular sensible bajo el régimen de la síntesis: hace de cada caso un elemento de una serie o conjunto. La danza de los reflejos del fuego en las paredes de la caverna, percibida bajo todas las síntesis del texto platónico sobre la esencia de la educación $\left(\pi \alpha \iota \delta \varepsilon^{\prime} \alpha\right)$. Lógica heliocéntrica de gobierno, la síntesis alegórica pone a lo sensible y singular como caso particular de un universal, de una forma separada. De un separable ( $\chi \omega \rho i \sigma \tau o \nu)$, en términos de Aristóteles, o, en la curva romana del latín, de una abstractio. Ahora bien: lo mismo, precisamente, hacen las instituciones. Los singulares se gobiernan o son gobernados por una dimensión formalizada de políticas y policías, jerarquías e identidades, procesos, procedimientos, normas. Las instituciones se anquilosan y reniegan de su carácter relacional e instrumental, volviéndose máquinas tendencialmente autotélicas.

Lezra formula provocativamente lo que, en relación con la cuestión de la institución, detecta en el trabajo tardío de Paul de Man como un gesto de "deconstrucción afirmativa": proyectar la posibilidad de construir "instituciones que vinieran a responder, y nunca a completar, el trabajo de la deconstrucción". No se trataría, en sentido estricto, de una "puesta en obra" de la deconstrucción, pero tampoco de su pura substracción operativa, sino de una puesta en juego. Contra el dictum de Schlegel sobre la negatividad pura de la crítica: instituciones deconstructivas. Se trataría de poner en juego un concepto ilimitable de institución, como se insinuaría en los trabajos de Emile Benveniste ${ }^{5}$, o como ocurre con la institución del lenguaje, para decirlo en los términos de Ferdinand

J. Lezra, “Alegoría e institución en Paul de Man”, en Cátedra Internacional Adolfo Couve, organizado por el programa de Doctorado en Filosofía con mención en Estética y Teoría del Arte, de la Facultad de Artes de la Universidad de Chile, conferencia del 21 de junio de 2017, en Santiago de Chile.

E. Benveniste, Le vocabulaire des institutions indoeuropéennes, $\mathrm{Pa}$ ris, Les Éditions de Minuit, 1969. de Saussure ${ }^{6}$, entre la reducción a lo uno de la langue y la diferencia de la parole: la institución lingüística ostenta una tendencia homogeneizante en cuanto lengua, pero también una tendencia heterogeneizante en cuanto a la materialidad de la palabra hablada. Se trataría, pues, de pensar una institución como construcción defectiva, efimera, declinable en la gramática de los modos y no en la de la substancia. En el archivo de Paul de Man en la Universidad de California Irvine hay un manuscrito, "Textual Allegories", que forma parte de elaboraciones teóricas que están a la base de lo que será Allegories of Reading, el libro de 1979. Según Lezra, se puede hallar en él un intento tardío de Paul de Man de pensar la política y sus instituciones.

Si el concepto de institución fuerte implica el paso de la aberración espontánea de los singulares hacia la relación recíproca de mutuo reconocimiento a una ley, entonces tal concepto performa un poder: la reducción de los singulares a la matematización de una unidad o campo económico tropológico, campo compartido por singulares devenidos particulares en virtud del régimen sintético. Es como funcionan tradicionalmente la alegoría y la institución, con sus fronteras, integridades y clausuras. Si se trata aquí de un De Man lector de Husserl, entonces podríamos decirlo fenomenológicamente: a toda intuición, en cuanto acto de percibir-pensar, corresponde algo percibido-pensado, el noema. Este correlato noemático corresponde al significado como referente en la estructura lingüística -sentido de una cosa, juicio, sujeto o dios-e implica la proyección intencional de una forma o unidad ideal de sentido bajo la cual se subsumen la materia de los "ingredientes reales" de la vivencia y sus "residuos hiléticos". Este noema o estructura sintética y unitaria, en "actitud natural" - para decirlo con Husserl, pues a él se está refiriendo Paul de Man-, adquiere "los atributos de la existencia natural". En virtud de la misma estructura lingüística de referencialidad el correlato noemático se "naturaliza": en un movimiento de acumulación ontológica originaria, adquiere los rasgos categoriales de la substancia -autosubsistencia, consistencia, constancia, unidad y coherencia, autotelia, independencia respecto del sujeto, a la vez que síntesis secreta de su constitución.

El noema se fetichiza, se torna una trascendencia naiv, y allí entra en juego la deconstrucción de esta metafísica de la presencia y sus sedimentaciones -más allá de la recaída metafísica del sujeto trascendental fenomenológico. La deconstrucción entra en juego abriendo una fisura entre la repetición constatativa y la emergencia performática, entre la institución en sentido nominal (la institución dada) y la institución en sentido verbal (el acto instituyente); entre el orden representable al que nos adecuamos (óplótns, adaequatio) y la potencia instituyente de la imaginación común e irreductible ${ }^{8}$. En este horizonte, Paul de Man, como pensador de la insti-

F. Saussure, Course de linguistique générale, Paris, Éditions Payot \& Rivages, 1995.

P. De Man, "Textual Allegories (1973)", Irvine, California, University of California Irvine Libraries, Special Collections and Archives, Critical Theory Archive.

Para pensar la tensión interna entre forma y evento, ver la Introducción de Jacques Lezra a C. Diano, Form and Event. Principles for an 
tución, abriría un umbral que habilitaría el pensamiento de una suerte de deconstrucción afirmativa en relación con la cuestión de la institución: pensarla como un movimiento inmanente de la vida entre la maximización del lenguaje y su desobramiento. La indecidibilidad entre las palabras y las cosas. Entre el nominalismo de las palabras que originan a las cosas y el realismo las cosas que originan a las palabras, hay un umbral de indecidibilidad y terror.

Un pensamiento cercano a los de Marx o Nietzsche, para quienes el significado, lejos de ser algo "originario", es producto proliferante de relaciones de poder y significación. ¿Cómo pensar la institución del noema y el noema de la institución como un sistema dinámico de relaciones entre signos sin centro ordenador, a diferencia de las ideas "platónicas" que son significados originarios-unificadores, a los que las cosas-signos se refieren miméticamente como tales? Se trata esta última de una interpretación absolutamente heliocéntrica de la idealidad platónica, por supuesto, pero que tradicionalmente ha hecho juego, al menos fantasmáticamente, con cierto organicismo moderno que comprende que el orden de la "estructura" estaría dado por tendencias a la inclusión (autorregulación, lo mismo) y la exclusión (delimitación, lo otro) en equilibrio dinámico (orden en transformación o transición).

\section{La institución del noema}

Quizás uno de los lugares donde destaca con más fuerza la curva monstruosa de la maximización moderna del lenguaje como institución fuerte -en términos de metafísica de la presencia, como reducción a lo uno, principialidad e identidad- es en los trabajos de Edmund Husserl $^{9}$. Del lenguaje proliferante y anexacto a la dimensión unitaria, subjetivo-trascendental y principial del eidos y la norma - tal como ya se halla de antiguo tal curva, por ejemplo, entre las teorizaciones de Aristóteles sobre la significación que concierne a los animales en general en su habitar y sus tratados sobre el lenguaje metafísico principial desplegado por los animales humanos en virtud de su vínculo lógico con lo divino.

En Husserl la reducción a lo uno opera como reducción de la multiplicidad de los "ingredientes reales" (reelle Bestand) del acto de pensar algo a la unidad y "atemporalidad" del elemento eidético. La idealidad, al ser función de unidad y permanencia, reúne trascendentalmente nuestras experiencias intransferibles en la comunicación -hace posible una suerte de "telepatía" como comunión en el elemento ideal del lenguaje que unifica el sentido. Si el análisis de Franz Brentano había prestado especial atención al acto de pensar (noesis,

Interpretation of the Greek World, New York, Fordham University Press, 2020.

9 Cf. E. Husserl, Logische Untersuchungen I (1900, Prolegomena zur reinen Logik), Tübiengen, Max Niemeyer Verlag, 1993; Logische Untersuchungen II (1901, Untersuchungen zur Phänomenologie und Theorie der Erkenntnis), Max Niemeyer Verlag, Halle a. Saale, 1901; Ideen zu einer reinen Phänomenologie und phänomenologischen Philosophie I (1913), en Husserliana, 3, 1950, y Die Krisis der europäischen Wissenschaften und die transzendentale Phänomenologie (1936), en Husserliana, 6, 1976. cogito, intentio) y la tipología de sus modos de apertura en el campo de la "psicología", el de Husserl -al menos en sus años en Halle- la prestará más bien a la "lógica", es decir, al intentum o polo objetivo (noema, cogitatum) de la correlación intencional estudiada por la fenomenología. Sedimentado históricamente, en cuanto a priori fáctico, el noema tiene un carácter "intersubjetivo": trasciende los actos -reúne su multiplicidad intransferible de "ingredientes reales" en la comunión de la unidad ideal del sentido (ideale Einheit der Sinne). Husserl habla de una intuición categorial (kategoriale Anschauung), una intentio que tiene el carácter de un "ver intelectual". También habla de abstracción ideatoria (ideierende Abstraktion), visión de la esencia (Wesenschau) o intuición de la esencia (Wesensanschauung).

El correlato intencional objetual de esta intentio, su intentum, es la esencia (Wesen, eidos), el evento de sentido -y correlato del sueño de la fenomenología con "lo originario". Husserl es cuidadoso, por supuesto. Por una parte "la esencia se $d a$ " -no es algo que sólo esté "en la mente": es datum, positum, contra el "psicologismo" y su confusión de esferas al reducir lo lógico a lo psíquico. Pero se trataría de pensar lo dado (Selbstgegebenheit) sin "hipóstasis metafísica" ni "ceguera positivista". Pensar lo dado sin hipóstasis metafísica significa: sin substancialización, ni por el lado del sujeto (se da, pero no es algo subjetivo en el sentido del sujeto empírico como centro) ni por el lado del objeto (se da, pero no como algo substancial, sino como evento de sentido). Y pensar lo dado sin ceguera positivista nos remite a una célebre proposición de Husserl que reza: "los fenomenólogos son los auténticos positivistas"10 -fórmula expresada en Ideas I pero ya desarrollada, formalmente, en la célebre sexta investigación lógica. En una lectura posible de Platón, los fenomenólogos serían quienes consideran el campo de la intuición como el "campo íntegro" de lo dado (datum, positum), de lo dado "tal como se da", en tanto se da esencialmente como hecho ya articulado en su interpretación (sentido) por lo ideal. El campo íntegro de lo dado en la intuición, el fenómeno (Phänomen), implica lo empírico (sensible) y lo lógico (ideal) -como suelo y horizonte histórico de sentido espiritualmente sedimentado-, y sólo la consideración de tal coimplicación provee al fenomenólogo de un genuino acceso hermenéutico "a las cosas mismas" (zu den Sachen selbst).

Para justificar su hipótesis fenomenológica respecto de la autonomía de la esfera de lo lógico de cara al psicologismo, entre sus tempranas investigaciones lógicas y sus reflexiones sobre la crisis de las ciencias europeas, Husserl ofrece varios argumentos. Hay dos que me parecen decisivos, pero voy a llamar la atención después de todo sobre el segundo. El primer argumento se encuentra como centro de gravedad ya desde el incipit de las Investigaciones lógicas (1900), pues se trata de la distinción entre el ser real (factual, empírico) y el ser ideal (esencial, categorial): el ser ideal es irreductible a los hechos psicológicos, pues su sentido y validez (universalidad y necesidad) trasciende la dimensión meramente factual del acto de pensamiento. Lo ideal no es un "ingrediente

10 E. Husserl, Ideen zu einer reinen Phänomenologie und phänomenologischen Philosophie I, op.cit., p. 46. 
real" (reel) del acto. El acto de pensar no es lo mismo que el objeto del pensamiento. El acto sucede en el tiempo, su duración es finita, todos son distintos (actos de distintos sujetos o actos de un mismo sujeto en distintos momentos del tiempo). El objeto es una "unidad ideal de sentido", se caracteriza por su validez atemporal y por su identidad (pese a que se instancie en distintos actos de pensamiento).

El segundo argumento respecto de la autonomía de la esfera de lo lógico de cara al psicologismo atraviesa como eco de una inquietud fundamental el texto de la Crisis (1936) y su filosofía de la historia, dando cuenta de su carácter restaurador, restitutivo o transicional: el lenguaje, la vida cotidiana y la ciencia -es decir, toda institución racional (vernünftig Stiftung)- se mueven en la esfera de la "racionalidad" (idealidad, universalidad y necesidad), distinta de la esfera de la factualidad (singularidad, caso y contingencia). El lenguaje, la vida cotidiana y la ciencia presuponen la idealidad como condición de posibilidad de su estabilidad y comunicabilidad: conocer, reconocer, nombrar. A diferencia de los actos, que son incomunicables, pues nadie se puede poner literalmente en el lugar de mis actos: sólo podemos comunicar ideas mediante signos que indican significados establecidos y convencionales. El problema de la lógica y la fundamentación de las ciencias en Husserl implica de este modo una inquietud ético-política: si la verdad racional de lo lógico y lo matemático es una cuestión de hecho -como propugna el psicologismo-, tal verdad de lo racional está sujeta a la contingencia de lo factual. Más allá del problema formal y práctico de la comunicabilidad, políticamente esto implicaría que la vida en común fundada en el derecho (racionalidad) estaría sujeta a la fuerza de los hechos (factualidad) y, por lo tanto, el derecho se fundaría en la violencia (poderes fácticos, guerras, dictaduras, revoluciones). A Husserl le preocupa la estabilidad lógica del mundo de la vida. Pero parece no pensar la relación entre derecho y violencia más allá de la hipótesis hobbesiana y el dispositivo cristiano de la persona.

Si en la relación entre vida y forma la forma es anterior a la vida, a la vida no le cabe otra relación con la forma que no sea la obediencia. En el pensamiento de Husserl la hipótesis en juego es, en su forma más general, que la percepción de lo sensible está ya articulada por lo ideal. Ya en su temprana crítica a Brentano sostenía que no hay percepción-representación antes que juicio y emoción: la representación no es un estrato subyacente y neutro sobre el cual vendrían a operar otros actos que le aportarían sentido. Según Husserl, todos los tipos de actos intencionales (percepción-representación, emoción, juicio) son co-originarios y se hallan entretejidos. La emoción y el juicio no operan "sobre" un acto de representación subyacente: en el acto de representación ya está implícito el encaminamiento del juicio, la decisión judicativa, además de un determinado tono emocional. Sin embargo, tal hipótesis va de la mano en Husserl de una idea de filosofía fenomenológica como "funcionariato de la humanidad", de la cual la universidad sería la institución misionera moderna por antonomasia: la filosofía universitaria tendría por misión la profesión infini- ta de aclarar los marcos hermenéuticos para el gobierno de la vida, en el contexto de la racionalidad occidental de matriz greco-cristiana que configura su filosofía de la historia secular como "civilización". Se trata de una filosofía de la historia que piensa en términos de sedimentación historiológica, claro está, pues lo de Husserl, a pesar de romper con Kant al introducir su concepto de intuición categorial (kategoriale Anschauung), no es una metafísica "dogmática" en el sentido prekantiano.

Las respuestas a este estado de la cuestión, en el curso de la cruenta escena material de la historia y el pensamiento del siglo XX, fueron múltiples y contundentes. La de Jacques Derrida nos asalta de inmediato, célebre, muy importante ${ }^{11}$. También está el trabajo monumental de Reiner Schürmann y su crítica a la idea de un pensamiento funcionario o humanismo universitario, en la medida en que la filosofía -0 , como habría que mostrar, la potencia de un pensamiento no enmarcado en la función filosófica "profesional" o "universitaria"tendría como rendimiento el desmontaje de las condiciones "epocales" de nuestro habitar, ${ }^{12}$ sus racionalidades hegemónicas de carácter teo-onto-antropológico - $\mathrm{O}$ sus epistemes, para decirlo con Foucault. Instituciones de ensambles tecnológicos entre teologías políticas articuladoras de órdenes jerárquicos, sacrificiales, y ontologías fundamentales como economías de la presenciación -que implican la propia presencia de "lo humano" sacralizada en antropologías teológicas, filosóficas, o en alguno de sus sucedáneos etnográficos tardíos.

En el caso del trabajo de Jacques Lezra, lo que abre es la posibilidad de pensar una ontología otra -no teo-ontoantropológica-, que habilite una cosmología heteróclita y una república material o salvaje ${ }^{13}$. Una inflexión ontológico-lucreciana, ni jerárquica (soberanía unitaria, teología política) ni atributiva (identidad, economía de la presencia). Un materialismo aleatorio del clinamen, que desplaza la noción aristotélica de "accidente" -la noción atributiva, relativa a la substancia- por la noción lucreciana de "contingencia" -que implica aleatoriedad, apertura, encuentro y desvío ${ }^{14}$. En su momento, Platón enfrentó la dimensión material de la historia en su carácter aleatorio y conflictivo -ya sea pensando la guerra civil $(\sigma \tau \dot{\alpha} \sigma \iota \varsigma)$ en "República", ${ }^{15}$ ya sea en el "Timeo"16 pensando en esa dimensión del no-lugar-que-da-lugar

J. Derrida, La voz y el fenómeno. Introducción al problema del signo en la fenomenología de Husserl, trad. Patricio Peñalver, Valencia, Editorial Pre-Textos, 1985.

12 R. Schürmann, Broken Hegemonies, trad. R. Lilly, Bloomington, Indianapolis, Indiana University Press, 2003, p. 6.

13 J. Lezra, República salvaje. De la naturaleza de las cosas, Santiago de Chile, Ediciones Macul, 2020. Además, cf. S. Villalobos-Ruminott, "La querella de las cosas. Marx, Lucrecio y el desorden del mundo", Revista Internacional Oxímora, 17, 2020, pp. 119-134; y G. Díaz-Letelier, "Singularidad, forma y gobierno. Lucrecio y los términos de un republicanismo material y salvaje", Revista Internacional Oxímora, 17, 2020, pp. 139-145.

14 J. Lezra, Jacques, Wild Materialism. The Ethic of Terror and the Modern Republic, New York, Fordham University Press, 2010. Cf. también, Aguayo, Claudio, "Materialismo salvaje: terror, concepto débil y república", Revista Res Publica, 18, 2, 2015, pp. 445-450.

15 Platón, "По $\iota \iota \varepsilon i \alpha "$, en John Burnet (ed.), Platonis Opera, tomo IV, Oxford, Oxford University Press, 1903, 470b.

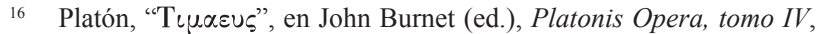
Oxford, Oxford University Press, 1903, 52b. 
( $\chi \omega \rho \propto)$ que se halla antes de toda posible relación mimética entre lo sensible y lo inteligible. Pero retrocedió - como más tarde lo hará Kant en su segunda edición de la "Crítica de la razón pura"- ante algo abismal y aterrador, conjurando lo que se le aparecía como la tendencia al no-ser del singular como lo último (ย̌ $\sigma \chi \alpha \tau o \nu$ ) -y subsumiéndolo o aniquilándolo en nombre del orden ideal de la república.

Lezra, como antes lo hicieran a su modo en cada caso Maquiavelo, Marx o Althusser, descubre una pedagogía del terror en el poema sobre la naturaleza de Lucrecio, una pedagogía que acoge ese secreto una y otra vez descubierto y olvidado como el corazón de un pensamiento serenamente espantado. Una pedagogía del terror que busca conjurar, además de la necia violencia supersticiosa y sacrificial de los hombres creadores de dioses, los efectos autoinmunes de una república ideal derivada de ello -sistemas morales y sociales basados en la autoridad de sistemas metafóricos incuestionables. Repensar lo político con Lezra lector de Lucrecio conlleva un movimiento o dislocación radical desde la estructura arborescente de la ontoteología política (el $\pi$ pós हैข o afirmación sacrificial de lo uno como incorporación orgánica bajo un principio trascendental) hacia la afirmación anárquica y no sacrificial de las multiplicidades inmanentes de lo vivo, proliferación de la vida pagana, de sus éjidos y sus heterocronías.

\section{Necrofilología}

Como si fuera una ontología modal barroca, la "expresión" de la potencia implica la "destrucción" del principio de representación que la captura. En ello se juega la imagen en fuga de la república de Lezra y sus instituciones defectivas. En su libro On the Nature of Marx's Things. Translation as Necrophilology ${ }^{17}$, de 2018, Lezra desarrolla, a partir de una reelaboración lucreciana del último Althusser, una teoría del concepto en Marx. Si la comprensión de las cosas como tales implica la conceptualidad, entonces antes de preguntar por el concepto de las cosas -los "objetos de primer orden"- habría que preguntar por el concepto del concepto, es decir, por los "objetos de segundo orden". Pero en virtud de una tensión deconstructiva con el doblez metafórico del lenguaje, y sin la garantía del sujeto trascendental como condición absoluta de síntesis, los conceptos defectivos u objetos de segundo orden de Lezra -las cosas de Marx- no son como los objetos ideales de Husserl. Sin sujeto trascendental ni autosubsistencia noemática, por contraste con toda pretensión de unidad ideal de sentido, de reducción a lo uno y mímesis, de principialidad e identidad, los objetos de segundo orden de Lezra están bajo el índice de la inestabilidad ontológica: catástrofe, dinamismo no teleológico, deriva entrópica, descarrilamiento. Lejos de ser un concepto substancial o eidéticamente esencialista, el concepto "defectivo" es un concepto material y relacional, en permanente traducción.

17 J. Lezra, On the Nature of Marx's Things. Translation as Necrophilology, New York, Fordham University Press, 2018.
Para mí la "debilidad" o el "defecto" del concepto (...) depende de la "materialidad" de éste (...). Los conceptos en general son materiales, en cuanto no idénticos a sí mismos. Aquí el análisis en Materialismo salvaje pasa por el encuentro Althusser-Miller-Lacan, para buscar esta fórmula: el concepto de la auto-identidad del concepto no es auto-idéntico. Esta no-identidad-consigo del "concepto" de auto-identidad del concepto es un defecto formal de la filosofía del concepto, y como tal, se puede aplicar a todo concepto (el concepto "rojo", el concepto "estado", el concepto "animal", "casa", etc.), pero por eso mismo me parece, aunque interesante analíticamente, menos decisivo que un segundo defecto, que tiene que ver con la construcción histórica de los conceptos -es decir, con la producción de los conceptos, o con el devenir-concepto, en un momento, de tal o tal término, devenir que brota de estructuras débiles como efecto imprevisible de éstas, y cuya lógica cae fuera de lo que acabo de llamar el dispositivo de la estructura. Este "brotar" del concepto (...) es un fenómeno en el que se conjugan la circunstancia histórica, y el efecto de estructura. Para mí, el materialismo es la dinámica, lógico-histórica, de esta conjugación, que podría también pensarse como la 'relación' (en el sentido fuerte, verbal: el relacionar) entre/de estructura y coyuntura (recordemos que conjugar es querer someter al yugo: es decir, querer domar, querer actuar violentamente para entrar en el ciclo de la producción o de la reproducción, con fines agrícolas o domésticos, en todo caso sociales; buscar o crear cónyuges; pero también vale someter y someterse a la gramática de la persona, que impone, precaria y efímeramente, el yugo del tiempo verbal); y la materia es lo que impulsa, pero lo que también resiste, esta conjugación ${ }^{18}$.

En este punto Jacques Lezra propone, a partir de su teoría materialista del concepto defectivo, otra relación con el lenguaje: la necrofilología. En la medida en que, desde una suerte de ontología modal, Lezra disuelve la distinción entre ontología y epistemología, su materialismo concibe, en un solo movimiento, la naturaleza relacional y quiasmático/conflictiva entre las cosas y entre las ideas. Entre la lógica de Aristóteles articulada por los principios de identidad y no-contradicción -que sigue en vigor en la lógica fenomenológica de Husserl- y la necrofilología inspirada en Marx propuesta por Lezra hay un abismo. Si hay una modalidad de nuestra relación con el lenguaje que ilustra la catástrofe de la necrofilología es la traducción: relación entre distintos lenguajes, relación que en cada caso trastoca la coherencia interna de las "entidades" relacionadas ${ }^{19}$. Que la necrofilología dé cuenta de que después de Marx no se puede llegar $\mathrm{y}$ discursear conceptualmente sobre objetos físicos o conceptuales, sino que ante todo haya que reflexionar sobre la forma de conceptualizar, implica que la necrofilología es una politización de la estética -más allá de toda captura de la potencia de la imaginación en una determinada organización fotológica de la imagen. Que la "necrofilología" (materialismo aleatorio) se oponga a las "filologías de la vida" (vitalismo organicista) signifi-

\footnotetext{
18 Lezra, "Materialismo y soberanía divisible. Entrevista con Jacques Lezra", Revista Demarcaciones, 3, 2015, s/p.

19 Lezra, On the Nature of Marx's Things. op.cit, pp. 10 ss.
} 
ca que en ella no se trata de conceptos/cosas tendencialmente orgánicas -"fábricas autopoiéticas de "vida»"-, sino de dinámicas polémicas y fragmentarias de formación de conceptos/cosas con potencial deformante y transformador. En ese sentido la necrofilología pone en juego una interrupción de la comunicación en el medio de la concepción burguesa de la lengua: en la medida en que no trascendentaliza significados, la necrofilología no produce positividades, sino que las interrumpe y las desobra. Esta disposición en su puesta en juego pone al pensamiento de Lezra en tensión con pensamientos como el de Schürmann, e incluso con el de Foucault, en la medida en que renuncia a la monumentalización "epocal" o "epistémica" de "economías organizadas de fuerzas y significaciones hegemonizadas según un orden principial y epocalmente distinguible" 20 .

Entre Descartes y Husserl se dibuja un interesante arco que va del sujeto soberano al sujeto funcionario. Edward Said escribía, hace ya casi medio siglo, sobre el sujeto soberano, fundante y fundamento:

La conciencia, ya sea como pura universalidad, irremontable generalidad, o actualidad eterna, tiene el carácter de un ego imperial; en esta perspectiva, el argumento cogito ergo sum era para Valéry "como un clarín tocado por Descartes para invocar los poderes de su ego". El punto de partida es la acción reflexiva de la mente atendiendo a sí misma, dejándose efectuar (o soñar) una construcción de un mundo cuya semilla implica totalmente su resultado ${ }^{21}$.

Y poco más adelante, sobre el sujeto funcionario y su profesión infinita de aclarar una y otra vez los marcos hermenéuticos para el gobierno de la vida: "Husserl merece especial atención, dado que la excesiva pureza de su proyecto filosófico completo hace de él, pienso, el epítome de la mente moderna en busca de comienzos absolutos; él ha sido bien llamado el perpetuo Anfänger (comenzador)"'22.

¿Qué formas asume hoy este funcionariato que consiste en administrar el arte de la institución de los conceptos y las interpretaciones, de los sujetos y los objetos? Si la institución universitaria moderna es el sucedáneo reflexivo de la institución eclesiástica teológica (Willy Thayer) ${ }^{23} \mathrm{y}$, como institución garante de la racionalidad del mundo de la vida, ella vigila aún el arte de los conceptos y la lectura -su tecnología-, Jacques Lezra introducirá la necrofilología en el campo de las "humanidades" contemporáneas para la desobra de la articulación entre pensamiento y vida, y no sólo contra la teología política, sino también contra las máquinas axiomáticas contemporáneas que operan apuntaladas por los remanentes más o menos secularizados o residuales de la teología. No sólo se trata de pensar la cuestión de la política estatal moderna y su granja biopolítica más arcaica, sino también la

\footnotetext{
S. Villalobos-Ruminott, op. cit., p. 127.

21 E. Said, Beginnings. Intention and Method, New York, Basic Books Publishers, 1975, p. 48.

22 Idem.

23 W. Thayer, La crisis no moderna de la universidad moderna. Epílogo del conflicto de las facultades, Santiago de Chile, Editorial Cuarto Propio, 1996.
}

interfaz ampliada y flexible de producción de objetos y sujetos en el capitalismo global tardío.

\section{De la soberanía a la interfaz ampliada del capitalismo}

Por una parte Lezra piensa contra la teología política y su figura del sujeto soberano ${ }^{24}$. La ontología materialista sobre la que descansa la república salvaje de Lezra es aleatoria y plural, y por consiguiente defectiva en lo que respecta a las funciones de fundación y fundamentación: se trata de una república sin fundamento, compuesto contingente cuya institución tiene más el carácter poemático del evento que el carácter hímnico de la substancia ${ }^{25} \mathrm{u}$ obra de un autor que tiene que realizarse a como dé lugar. En este sentido, la política lezriana del clinamen se pondría en juego contra la reducción a lo uno de la soberanía schmittiana y todo vestigio residual de teología política.

Por otra parte Lezra piensa contra las máquinas axiomáticas del capital y su figura de sujeto funcionario -en el actual contexto de abstracción del capitalismo, virtualización de la experiencia y universalización de las equivalencias. Lezra advierte que la reproductibilidad global de la forma-valor del capital implica hoy una "maquinaria de la traducción" (translating machine). El violento poder de captura y borradura de la diferencia y del conflicto que pone en juego la máquina de traducción moderna - de la que la universidad hace parte, por supuesto- funcionaría en orden a la producción de

(...) subjetividades reconocibles entre sí, asociadas sobre la base mínima de ese reconocimiento, capaces de realizar transacciones de tipo económico, social y lingüístico sobre esa base. / (...). Maquínica, captura las funciones incompatibles de la traducción y los registros semánticos y los traduce a un campo regulado y claro: un sistema de asignación de valores (económicos y de otros tipos). Hace que la transferencia de derechos a otros (humanos, animales, instituciones, posiciones) y el reconocimiento de otros como portadores de derechos se apoye en ficciones. Llamamos a este núcleo duro y anti-humanista en el corazón de la universidad con el nombre de "máquina de traducción"26.

En su ensayo "Spanish Type"27, Jacques Lezra propone pensar la dinámica entre traducibilidad e intra-

\footnotetext{
24 Un tratamiento temático de esta cuestión se halla, por ejemplo, en J. Jacques, "The Instance of the Sovereign in the Unconscious: The Primal Scenes of Political Theology", en Graham Hammill y Julia Reinhard Lupton (eds.), Political Theology and Early Modernity, Chicago, University of Chicago Press, 2012.

25 R. Karmy, "La copia feliz del Edén. La gloria de un himno y el desgarro del poema", Revista de Filosofia, 67, 2011, pp. 41-54.

26 J. Lezra, "Translation", en Mercedes Bunz, Birgit Kaiser \& Kathrin Thiele (eds.), Symptoms of the Planetary Condition: A Critical Vocabulary, Lüneburg, Meson Press, 2016, pp. 229-230.

27 J. Lezra, "Spanish Type", ensayo en inglés que inicialmente fue una conferencia magistral en español pronunciada en el Museo Nacional de Bellas Artes (Santiago, Chile), en el marco del encuentro internacional "Challenges of Translation. Translation's Theoretical Issues, Practical Densities: Violence, Memory, and the Untranslatable" (1526 de julio de 2017), organizado por el Centro Interdisciplinario de Estudios en Filosofía, Artes y Humanidades (CIEFAH) de la Universidad de Chile.
} 
ducibilidad en relación con el modo de producción de valor en los tiempos del capitalismo global. Para pensar esta cuestión y la posibilidad de una salida a su aporética, parte señalando tácitamente hacia la "concepción burguesa de la lengua" expuesta por Walter Benjamin en sus textos sobre la narración, sobre la traducción y sobre el lenguaje animal en general y el humano en particular: la lengua como "medio de comunicación de significados", por analogía al "comercio de mercancías" -todo esto, podríamos decir, ligado a la crítica del fetichismo de la mercancía en el primer libro de Das Kapital de Marx, pero leído en clave estética, es decir, como crítica de las formas occidentales de la imaginación y sus rendimientos económico-políticos. En los términos burgueses o modernos de la máquina traductiva, "lo traducible" -ya sea en el mismo idioma o entre idiomas diferentes- es lo comunicable mutatis mutandis (guardando las diferencias), por aproximación pragmática, es decir: aquello que pese a las diferencias de referente, contexto y significantes (no es lo mismo decir "hace frío" en Chile que decir "It's cold" en California), a pesar del juego de las diferencias y la ausencia de identidad o presencia plena y originaria, puede ser "comunicado", "sin mayor problema",

(...) la traducibilidad general que constatamos a nivel del idioma o de la expresión tiene la forma exacta del mercado global, en el que las mercancías circulan, se producen en tal sitio para consumirse en otro, con valores diversos pero relacionados. La traducibilidad general del valor tampoco está sujeta a identidades - cierta mercancía puede valer más o menos en tal o cual lugar, puede incluso ser otra cosa según el marco cultural, la historia, la ecología, los recursos locales-, pero las diferencias o bien añaden, o restan, valor, según principios que se revelarían, por eso mismo, universales: principio o sintaxis del mercado de los mercados, del mercado global ${ }^{28}$.

Hay, pues, una relación entre el moderno principio de traducibilidad general que permite la circulación de los significados puestos en valor semántico, por una parte, y el principio de equivalencia general del capital que permite la circulación de las mercancías puestas en valor económico. Traducción infinita y flexible del valor de uso singular e intraducible, como caso particular de un valor de cambio universal: subsunción real de la diferencia al proceso de valorización flexible del capital global. La metafísica de la presencia que se juega en la trascendentalización del significado, en la fetichización, clización o tipificación de la percepción, la apreciación y los relacionamientos, rinde como conversión del singular y su diferencial en "caso" particular de una universalidad fantasmática. Sin embargo, ya estamos advertidos de que en lo "singular" y su "intraducibilidad" hay un peligro, una trampa que abastece a la lógica del capital y su proceso de valorización flexible:

La hipótesis intraducible -que tiene el gran peligro, ya mentado, de caer en el nacionalismo ontológico o en el esencialismo lingüístico- preocupa sobremanera tanto a la filosofía contemporánea como al mercado universal. Tam- bién, claro, a la filosofía política: decir que tal expresión en inglés es intraducible por ser en inglés, nos permite afirmar que la peculiaridad del inglés necesita de dispositivos políticos para su afirmación o protección -un muro, un populismo etno-nacionalista, campos de concentración, la ideología trasnochada de una América que busca ser "grande" de nuevo. Buscamos, pues, afirmar la hipótesis intraducible, sin caer en el nacionalismo ontológico ${ }^{29}$.

La "trampa", si se quiere, es la que con mucha fuerza, desde la filosofía universitaria conservadora alemana del siglo XIX, por ejemplo, abasteció las estrategias de refugio en la idiosincrasia, en las Weltanschauungen peculiares de los "mundos de la vida" frente al universalismo liberal de la equivalencia general tecno-capitalista que arrasaba con las formas de vida tradicionales y "naturales". Y es que la "singularidad", para poder traducirse a esa maximización del lenguaje que es el "tipo", debe primero autoafirmarse identitariamente como presencia absoluta: como substancia, como entidad o positividad originaria, no relacional.

En este sentido Lezra parece apuntar al lazo o ensamble contemporáneo entre la equivalencia general de la traducibilidad -el "tipo" referido por Derrida- y el carácter babélico de la intraducibilidad -la singularidad fetichizada como tal en la forma "genérica". Lezra señala hacia Droit de regards, un texto de Jacques Derrida donde comparecen las fotografías de Marie-Françoise Plissart y una cita sin firma de Los espejos velados de Jorge Luis Borges. Se trata de un relato babélico, que pone en juego el diferencial de las interpretaciones, pero que sin embargo ofrece cierta legibilidad a partir de una serie de clichés circulantes acerca del "tipo español" -apasionado, celoso, dramático, monta-escenas, etc. El juego entre la singularidad y la tipificación es un juego de "veladuras": la universalidad equivalencialmente traductiva del estereotipo vela al singular desmaterializando su diferencial, fetichizando su "génesis"; y la singularidad del tipo de la foto vela al universal del estereotipo encarnándolo -en una relación, si se quiere, de filiación encarnativa con él. La (in)traducibilidad lezriana no se trataría, pues, ni del "crisol de culturas" (melting pot) como fundición de varias culturas en una mezcla homogénea; ni del "multiculturalismo" como fetichización de identidades sin mezcla, en la distancia de la "tolerancia", la "folklorización" o el tráfico universitario de identidades como mercancías académicas. Lezra propone, en lugar de todo ello, un "concepto defectivo", material y diferencial, de traducción:

Desde la posición ventajosa de estos términos a veces violentamente antagónicos y desde los futuros a los que parece traducirse el campo semántico dividido de la "traducción", nos topamos con algo más que el razonable sistema contractualista de reconocimientos mutuos que parecen definir al animal humano en la traducción. / (...) Esa tarea es ayudar a resguardar y producir la violencia de la traducción, y en esta condición permitirnos imaginar, reflexionar y poner en marcha regímenes formales, efímeros y reversibles de asociación democrática que son incompatibles con lo humano 
en traducción. Es en esta máquina dentro de la máquina de la forma mercancía cultural reproductible globalmente, en este núcleo maquínico y anti-humanista, y sobre la base del no-reconocimiento, de la incoherencia del principio de traducción, que los regímenes democráticos pueden y deben hoy ser imaginados -es decir, producidos ${ }^{30}$.

\section{$* * *$}

El trabajo de Jacques Lezra, lejos de la contextura de la razón imperial hispana con su "lógica inquisitorial" -arqueológica, principial e identitaria, cercana a una tendencia filológica conservadora que se dedica a excavar hacia "lo originario"-, se inscribiría así en el campo de lo que Erin Graff Zivin llama las prácticas críticas anarqueológicas $^{31}$. Campo de prácticas teóricas que hoy, en medio de un capitalismo mundial desmaterializado, apuntalado por políticas estatales articuladas por teologías políticas vestigiales, y al fragor de luchas y revueltas moleculares de la imaginación popular, crisis ambientales y dramáticos encuentros con lo no-humano, hacen posible un pensamiento salvaje a la altura de la catástrofe y el conato desarticulador de sus máquinas de transferencia, fetichización y traductibilidad.

\section{Bibliografía}

Aguayo, C., "Materialismo salvaje: terror, concepto débil y república", Revista Res Publica, 18, 2, 2015, pp. 445-450.

Benveniste, É., Le vocabulaire des institutions indoeuropéennes, Paris, Les Éditions de Minuit, 1969.

De Man, P., "Textual Allegories (1973)", Irvine, California, University of California Irvine Libraries, Special Collections and Archives, Critical Theory Archive.

Derrida, J., "What is a «Relevant» Translation?”, trad. Lawrence Venuti, Critical Inquiry, X, 27, Chicago, 2001.

-, La voz y el fenómeno. Introducción al problema del signo en la fenomenología de Husserl, trad. P. Peñalver, Valencia, Editorial Pre-Textos, 1985.

Diano, Carlo., Form and Event. Principles for an Interpretation of the Greek World, trad. T. Campbell y L. Turtas, New York, Fordham University Press, 2020.

Díaz-Letelier, G., "Singularidad, forma y gobierno. Lucrecio y los términos de un republicanismo material y salvaje", Revista Internacional Oxímora, 17, 2020, pp. 139-145.

Graff Zivin, E., Anarchaeologies. Reading as Misreading, New York, Fordham University Press, 2020.

Husserl, E., Logische Untersuchungen I, Max Niemeyer Verlag, Tübingen, 1993.

-, Logische Untersuchungen II, Max Niemeyer Verlag, Halle a. Saale, 1901.

-, Ideen zu einer reinen Phänomenologie und phänomenologischen Philosophie I, en Husserliana, 3, 1950.

-, Die Krisis der europäischen Wissenschaften und die transzendentale Phänomenologie, en Husserliana 6, 1976.

Karmy, R., "La copia feliz del Edén. La gloria de un himno y el desgarro del poema”, Revista de Filosofia, 67, 2011 , pp. 41-54.

Lezra, J., "Alegoría e institución en Paul de Man", conferencia en Cátedra Internacional Adolfo Couve, organizado por el programa de Doctorado en Filosofía con mención en Estética y Teoría del Arte, de la Facultad de Artes de la Universidad de Chile, el 21 de junio de 2017 en Santiago de Chile.

-, República salvaje. De la naturaleza de las cosas, Santiago de Chile Ediciones Macul, 2020.

-, Wild Materialism. The Ethic of Terror and the Modern Republic, New York, Fordham University Press, 2010.

-, On the Nature of Marx's Things. Translation as Necrophilology, New York, Fordham University Press, 2018.

-, "Materialismo y soberanía divisible. Entrevista con Jacques Lezra", Revista Demarcaciones, 3, 2015, s/p.

-, "The Instance of the Sovereign in the Unconscious: The Primal Scenes of Political Theology", en Graham Hammill y Julia Reinhard Lupton (eds.), Political Theology and Early Modernity, Chicago, University of Chicago Press, 2012.

-, “Translation”, en Mercedes Bunz, Birgit Kaiser \& Kathrin Thiele (eds.), Symptoms of the Planetary Condition: A Critical Vocabulary, Lüneburg, Meson Press, 2016, pp. 229-230.

-, "Spanish Type", conferencia en el Museo Nacional de Bellas Artes (Santiago, Chile), en el marco del encuentro internacional "Challenges of Translation. Translation's Theoretical Issues, Practical Densities: Violence, Memory, and the Untranslatable" (15-26 de julio de 2017), organizado por el Centro Interdisciplinario de Estudios en Filosofía, Artes y Humanidades (CIEFAH) de la Universidad de Chile.

Marx, K., Diferencia de la filosofía de la naturaleza en Demócrito y en Epicuro, Madrid, Editorial Ayuso, 1971.

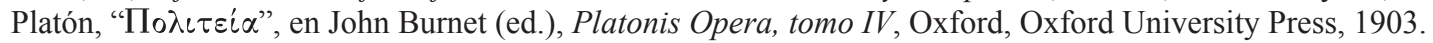

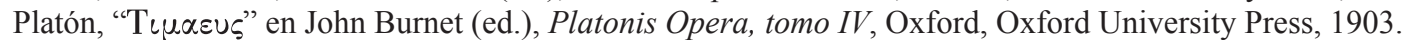

Said, E., Beginnings. Intention and Method, New York, Basic Books Publishers, 1975.

Saussure, F., Course de linguistique générale, Paris, Éditions Payot \& Rivages, 1995.

Schürmann, R., Broken Hegemonies, trad. R. Lilly, Bloomington, Indianapolis, Indiana University Press, 2003.

Thayer, W., La crisis no moderna de la universidad moderna. Epílogo del conflicto de las facultades, Santiago de Chile Editorial Cuarto Propio, 1996.

Villalobos-Ruminott, S., "La querella de las cosas. Marx, Lucrecio y el desorden del mundo", Revista Internacional Oxímora, 17, 2020, pp. 119-134. 